\title{
A FORMAÇÃO INICIAL DOS PROFESSORES ALFABETIZADORES DAS ESCOLAS PÚBLICAS DE SANTA CATARINA
}

\section{LITERACY TEACHERS' INITIAL TRAINING OF PUBLIC SCHOOLS IN SANTA CATARINA}

\section{LA FORMACIÓN INICIAL DE LOS PROFESORES ALFABETIZADORES DE LAS ESCUELAS PÚBLICAS DE SANTA CATARINA}

\author{
Leonete Luzia Schmidt ${ }^{*}$ \\ Universidade do Sul de Santa Catarina, Professora do Curso de Pedagogia e do Programa de \\ Pós-Graduação em Educação \\ Maria da Graça Nobrega Bollmann** \\ Universidade do Sul de Santa Catarina, Professora do Programa de Pós-Graduação em
} Educação

Camile Martineli Silveira***

Escola de Gestão Pública Municipal, Coordenadora de formação

Resumo: O artigo resulta de reflexões no âmbito da pesquisa realizada entre $2010 \mathrm{e}$ 2014, vinculada ao Programa Observatório da Educação - Capes/Inep. Busca socializar o quadro referente à formação inicial dos professores alfabetizadores das escolas públicas de Santa Catarina, em exercício no ano 2013, utilizando-se de dados do Censo Escolar. Parte-se da compreensão de que a formação dos professores é mediada pelo contexto sociocultural no qual está inserida e se realiza em uma perspectiva dialética, em um processo no qual se articulam teoria e prática, tendo a pesquisa como

\footnotetext{
*Doutora em Educação: História, Política, Sociedade pela Pontifícia Universidade Católica de São Paulo; Mestre em Educação pela Universidade Federal de Santa Catarina.

** Pós-Doutora em Educação pela Universidade de Lisboa; Doutora em Educação pela Pontifícia Universidade Católica do Rio de Janeiro.

*** Mestre em Educação pela Universidade do Sul de Santa Catarina; Especialista em Educação Especial pelo Centro Universitário Municipal de São José.
} 
base para essa formação. Os dados evidenciaram que no Estado de Santa Catarina a formação do professor alfabetizador apresenta fragilidades nessa perspectiva.

Palavras-chave: Política de formação de professores. Formação inicial de professores. Professores alfabetizadores.

Abstract: This article is the result of reflections within the survey conducted between 2010 and 2014, linked by the Education Centre Program-Capes/Inep. The research aims to socialize the current situation on the initial training of literacy teachers from public schools in Santa Catarina, who were working in 2013, using the School Census data. It starts with the understanding that the training of teachers is mediated by sociocultural context in which it is inserted and it operates and performs in a dialectical perspective, in a process that articulates theory and practice, and the research is the basis for such training. The data showed that in the State of Santa Catarina the formation of literacy teacher presents weaknesses in this perspective.

Keywords: Teacher education policy. Initial teacher training. Literacy teachers.

Resumen: El artículo resulta de reflexiones en el ámbito de la investigación realizada entre 2010 y 2014, vinculada al Programa Observatório da Educação-Capes/Inep. Busca socializar el cuadro referente a la formación de los profesores alfabetizadores de las escuelas públicas de Santa Catarina, en ejercicio en el año de 2013, utilizándose de datos del Censo Escolar. Se parte de la comprensión de que la formación de los profesores es mediada por el contexto sociocultural en el cual está insertada y se realiza en una perspectiva dialéctica, en un proceso en que se articula teoría y práctica, teniendo la pesquisa como base para esa formación. Los datos han evidenciado que en el Estado de Santa Catarina la formación del profesor alfabetizador presenta fragilidades en esa perspectiva.

Palabras clave: Política de formación de profesores. Formación inicial de profesores. Profesores alfabetizadores.

\section{INTRODUÇÃO}

A elaboração deste artigo resultou de reflexões no âmbito da pesquisa realizada entre 2010 e 2014, vinculada ao Observatório da Educação - Coordenação de Aperfeiçoamento de Pessoal de Nível Superior/Instituto Nacional de Estudos e Pesquisas Educacionais Anísio Teixeira (Capes/Inep), cujo objeto tratava da formação inicial e continuada e da prática docente dos professores alfabetizadores das escolas 
públicas de Santa Catarina. No decorrer da pesquisa, identificou-se a formação inicial e continuada dos professores, o tipo de instituição na qual se realizou essa formação, práticas de alfabetização na escola e fatores que contribuem para a melhoria da qualidade do processo de alfabetização nas redes de ensino. A intenção foi obter um diagnóstico que evidenciasse a realidade do Estado.

Neste texto teve-se como objetivo apresentar um recorte da pesquisa em que se mostra o quadro da formação inicial dos professores alfabetizadores das escolas públicas do Estado de Santa Catarina. Tomou-se, para fins de análise, o conjunto dos professores que atuam do $1^{\circ}$ ao $3^{\circ}$ anos do Ensino Fundamental, período em que devem ser assegurados a todas as crianças a alfabetização e o letramento em atendimento à Lei nacional n. 11.274/2006 e a outros dispositivos legais que dela decorrem. ${ }^{1}$ Os dados foram retirados do Censo Escolar de 2013, disponíveis nos microdados do Inep, sendo este o ano referência para as análises e reflexões aqui apresentadas. O Censo Escolar mostra que no Estado de Santa Catarina, em tal ano, havia 16.944 professores alfabetizadores, consistindo a base numérica sobre a qual se desenhou a análise da pesquisa apresentada como recorte neste artigo. Parte-se da compreensão de que a formação dos professores é mediada pelo contexto sociocultural no qual está inserida e se realiza em uma perspectiva dialética, em um processo no qual se articulam teoria e prática, tendo a pesquisa como base para essa formação. Considera-se também para essa compreensão que a formação de professores integra a política educacional brasileira, formulada a partir do embate de diferentes projetos de sociedade. Além disso, considera-se que

[...] é a formação inicial que vai habilitar o ingresso na profissão e deverá garantir um preparo específico, com um corpo de conhecimentos que permita ao profissional a condução do trabalho pedagógico e que, portanto, este profissional seja preparado para o domínio desse trabalho e para estabelecer relações que satisfaçam às necessidades para as quais ele foi formado. (ASSOCIAÇÃO NACIONAL PELA FORMAÇÃO DOS PROFISSIONAIS DA EDUCAÇÃO, 1996 apud BRZEZINSK, 2008, p. 1145).

Uma formação com essas características é condição para assegurar a alfabetização com letramento às crianças, condição necessária para garantir a continuidade nos estudos com a apropriação dos conhecimentos científicos e sua inserção na sociedade. 


\section{FORMAÇÃO INICIAL DE PROFESSORES ALFABETIZADORES: CONCEPÇÕES E INSTRUMENTOS LEGAIS}

Entender a formação inicial de professores alfabetizadores exige que se busque o modo como vem se realizando a formação de professores para a Educação Básica no Brasil, pois é nesse âmbito que a formação de professores alfabetizadores se insere. Considerando que a formação dos professores é definida ao longo da história na disputa por diferentes projetos político-ideológicos em um grau de complexidade e envolvimento de diferentes atores no âmbito do Estado, faz-se necessário buscar na história elementos para a sua compreensão.

Nesse sentido, Freitas (2002, p. 141), no início dos anos 2000, ao referir-se à história da formação de professores no Brasil, aponta a existência de diferentes perspectivas no âmbito dessa formação. Segundo ela,

[...] se a década de 1980 representou, para os educadores, o marco da reação ao pensamento tecnicista das décadas de 1960 e 1970, os anos 90, contraditoriamente, foram marcados também pela centralidade no conteúdo da escola (habilidades e competências escolares), fazendo com que fossem perdidas dimensões importantes que estiveram presentes no debate dos anos 80 .

A década de 1980 caracterizou-se, no Brasil, como um rico período de conquistas democráticas, especialmente para a educação pública, em que foram propostas “[...] mudanças na gestão e na organização da educação e a valorização do magistério como profissão.” (OLIVEIRA, 2008, p. 138). O clima de abertura política dessa época confluía para a democratização da educação e a participação coletiva nas tomadas de decisão desde a política educacional brasileira na sua totalidade, como no interior da escola que buscava vivenciar a gestão participativa.

Essa perspectiva democrática estava presente no âmbito da formação de professores caracterizada na relação teoria-prática, no caráter sócio-histórico e no desenvolvimento da consciência crítica que permite ao professor interferir para transformar as condições da escola, da educação e da sociedade.

Nesse sentido, foi criado, nos anos 1980, o Fórum Nacional em Defesa da Escola Pública com o intuito de intervir fortemente nos desígnios do País, na educação como um direito social, o que viria a se materializar em 1988 nos artigos 205 a 214, Capítulo III da Constituição Federal. Brzezinsk (2010, p. 187) chama o movimento de luta dos trabalhadores em educação, de mundo real, vivido, “[...] construído na luta dos educadores, travada desde os anos 1980 para resistir e tentar modificar 
as práticas autoritárias de traçar políticas educacionais consentâneas com interesses apenas dos que detêm o poder econômico e político em nosso país."

Nos anos 1990, contrariando essa perspectiva democrática presente na luta dos educadores na década anterior e indicando uma reedição da teoria do capital humano, ${ }^{2}$ tão em voga nos anos 1970, a educação torna-se crucial para enfrentar a competitividade acirrada, melhorar a produção e adquirir a tão propalada empregabilidade. Para Shiroma (2000), o ideário adjacente à política educacional da década de 1990 foi disseminado em nível global por publicações e eventos importantes patrocinados por agências como o Banco Mundial, a Organização das Nações Unidas para a Educação, a Ciência e a Cultura (Unesco), o Programa das Nações Unidas para o Desenvolvimento (PNUD) e o Fundo das Nações Unidas para a Infância (Unicef). Os diagnósticos, as análises e as propostas de soluções constantes nas publicações, tanto para a educação quanto para a economia, prestavam-se aos países da América Latina e do Caribe e influenciaram as políticas públicas para a educação (SHIROMA; MORAES; EVANGELISTA, 2002).

A Conferência Mundial sobre a Educação para Todos em Jomtien, na Tailândia, no ano 1990, considerada o grande marco das reformas que a seguiram, foi organizada pela Unesco, pelo Unicef, pelo PNUD e pelo Banco Mundial. Subscrita por 155 governos que assumiram o compromisso de assegurar uma Educação Básica de qualidade a crianças, jovens e adultos, resultou em consensos que deveriam penetrar a formulação dos planos decenais de educação, em especial nos países mais populosos e com os maiores índices de analfabetismo do mundo (SHIROMA; MORAES; EVANGELISTA, 2002).

Saviani (2009), ao se referir à formação de professores no Brasil, observa que a mobilização dos anos 1980 havia criado nos educadores brasileiros “[...] a expectativa de que, findo o regime militar, o problema da formação docente no Brasil seria mais bem equacionado." No entanto, ao ser promulgada a Lei de Diretrizes e Bases da Educação Nacional (LDB) de 1996, essa expectativa não fora correspondida.

Introduzindo como alternativa aos cursos de pedagogia e licenciatura os institutos superiores de educação e as Escolas Normais Superiores, a LDB sinalizou para uma política educacional tendente a efetuar um nivelamento por baixo: os institutos superiores de educação emergem como instituições de nível superior de segunda categoria, provendo uma formação mais aligeirada, mais barata, por meio de cursos de curta duração (Saviani, 2008c, p. 218-221). A essas características não ficaram imunes as novas diretrizes curriculares do curso de pedagogia homologadas em abril de 2006. (SAVIANI, 2009, p. 148). 
A LDB/1996 é resultado de “[...] disputa ideológica entre o público e o privado, tendo como foco a relação conflitante entre a defesa da escola pública e o ensino privado", este último não encontrando “[...] obstáculos da sociedade política para transformar em mercadoria o direito à educação preceituado na Constituição de 1988.” (BRZEZINSK, 2010, p. 190).

Assim, o caráter da política de formação de professores, desde os anos 1990 até o momento presente, tem a competência como conceito-chave, norteador do perfil de profissional a ser formado. A "pedagogia das competências" é a "pedagogia oficial" nas atuais políticas de formação inicial de professores, materializando-se não a partir dos avanços teóricos e práticos no campo da educação e da Pedagogia, mas a partir de exigências dos organismos internacionais promotores da reforma educativa nos diferentes países visando à adequação da educação e da escola às transformações no âmbito do trabalho produtivo. Para Aguiar (2010, p. 5):

Nas Diretrizes Curriculares Nacionais para a Formação de Professores da Educação Básica (Resolução $\mathrm{CNE}^{3} / \mathrm{CP} 4 \mathrm{n}^{\circ}$ 01/2002), é visível como o conceito de competências está fortemente vinculado à capacidade do professor em solucionar problemas imediatos, numa perspectiva pragmatista e produtivista. Esse modelo vem sendo incorporado, via formação de professores, à educação das novas gerações de modo que possa inseri-las, desde a mais tenra idade, na lógica da competitividade, da adaptação individual aos processos sociais e ao desenvolvimento de suas competências para a empregabilidade ou laboralidade.

A Associação Nacional pela Formação dos Profissionais da Educação (Anfope), na sua luta histórica pela formação de professores da Educação Básica, vem defendendo uma formação consistente nos cursos de licenciatura plena na universidade, firmada na relação teoria-prática e sustentada na pesquisa, requisito para a profissionalização docente. Trata-se de uma posição que se contrapõe a esse projeto de educação/formação voltado aos interesses do capital globalizado em que a pedagogia das competências e habilidades adquire centralidade.

Essa posição vai ao encontro da concepção da Anfope por considerar que uma formação sólida e consistente dos professores se constitui um dos elementos fundamentais para possibilitar uma educação emancipadora para crianças, jovens e adultos e para a construção de uma sociedade justa e igualitária para todos.

Aguiar e Scheibe (2010, p. 84), ao se referir à relação teoria e prática na formação do professor, partem desse mesmo entendimento, em que "[...] a especificidade do trabalho escolar requer a articulação entre teoria e prática (ação/reflexão/ 
ação), necessária para complementar as exigências da qualidade escolar e da sala de aula no processo mais amplo de profissionalização dos professores."

A realidade indica que para alcançar uma formação de professores com essa qualidade há ainda muito a se fazer, certamente necessitando de lutas e enfrentamentos, dado que se trata de uma proposição que não está atrelada aos interesses do mundo do trabalho e do capital.

Nesse sentido, considera-se relevante destacar o significado da Meta 15 do Plano Nacional de Educação (PNE), Lei n. 13.005/14, por prever que todos os professores da Educação Básica devem ter formação em nível superior em curso de licenciatura na área de conhecimento em que atuam. Essa Meta constitui-se na materialização das reivindicações propostas pelas entidades do campo da educação num movimento histórico de síntese das lutas pela formação docente, importante requisito à qualidade da educação em todos os níveis, nesse caso, da alfabetização.

A Meta 15 do PNE é um avanço no que se refere à formação de professores, principalmente se se considerar que, nos termos do artigo 62 da LDB/96, consta a formação plena em nível superior na universidade. No entanto, no caput desse artigo, contraditoriamente foi relativizada essa formação com a possibilidade de realizar-se em institutos superiores de educação, e para o exercício do magistério na Educação Infantil e nos cinco primeiros anos do Ensino Fundamental, é permitida a formação oferecida em nível médio na modalidade Normal.

Considera-se, também, nessa discussão, que para atuar no ciclo alfabetizador é essencial um trabalho docente qualificado, sustentado em uma formação acadêmica teórica consistente e sólida, o que exige que o conteúdo da Meta 15 do PNE deva ser efetivamente concretizado.

Considerando essas formulações é que se apresenta, a seguir, como se configurou em Santa Catarina, no ano 2013, a formação inicial de professores alfabetizadores.

\section{A FORMAÇÃO INICIAL DOS PROFESSORES ALFABETIZADORES DAS ESCOLAS PÚBLICAS DE SANTA CATARINA À LUZ DOS DADOS DO CENSO ESCOLAR DE 2013}

A partir do exposto anteriormente, em que se define como fundamental uma formação sólida e consistente do ponto de vista teórico, realizada em cursos superiores de licenciatura plena na universidade, que incorpore a pesquisa como princípio formativo e que desenvolva o compromisso social e político necessário à docên- 
cia, é que se realizou a análise sobre a formação dos professores alfabetizadores do Estado de Santa Catarina aqui apresentada.

Inicia-se essa análise apresentando-se, no Gráfico 1, os dados sobre o nível de formação desses professores.

Gráfico 1 - Nível de formação dos professores alfabetizadores de Santa Catarina

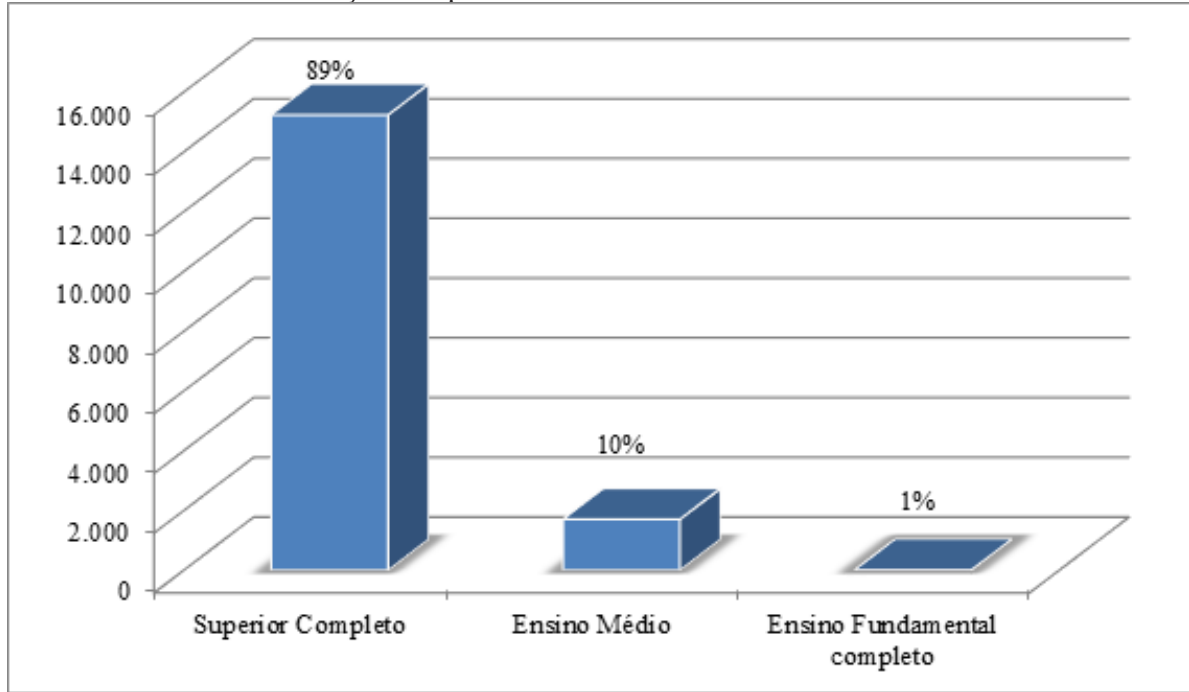

Fonte: adaptado do Instituto Nacional de Estudos e Pesquisas Educacionais Anísio Teixeira (2013).

A observação do Gráfico 1 sobre a formação geral dos professores alfabetizadores evidencia algumas fragilidades. Ainda que pareça que o problema da formação esteja praticamente resolvido, haja vista que aproximadamente $90 \%$ dos 16.944 professores em exercício no ano 2013 possuem curso de nível superior, em uma análise mais detalhada percebe-se que há limites, pois todos os professores devem ter formação condizente com o exercício dessa função. Diante disso, a maior fragilidade está no fato de que cinco professores possuem apenas formação no Ensino Fundamental.

Outro aspecto relevante refere-se à habilitação desses professores em nível médio. Os dados que aparecem no Gráfico 1 mostram que 10\% possuem a formação no Ensino Médio, correspondendo a 1.704 professores. Destaca-se que parte deles, como indica o Gráfico 2, constitui-se de professores leigos por não possuírem habilitação para o magistério. 
Gráfico 2 - Habilitação dos professores alfabetizadores com formação em nível médio

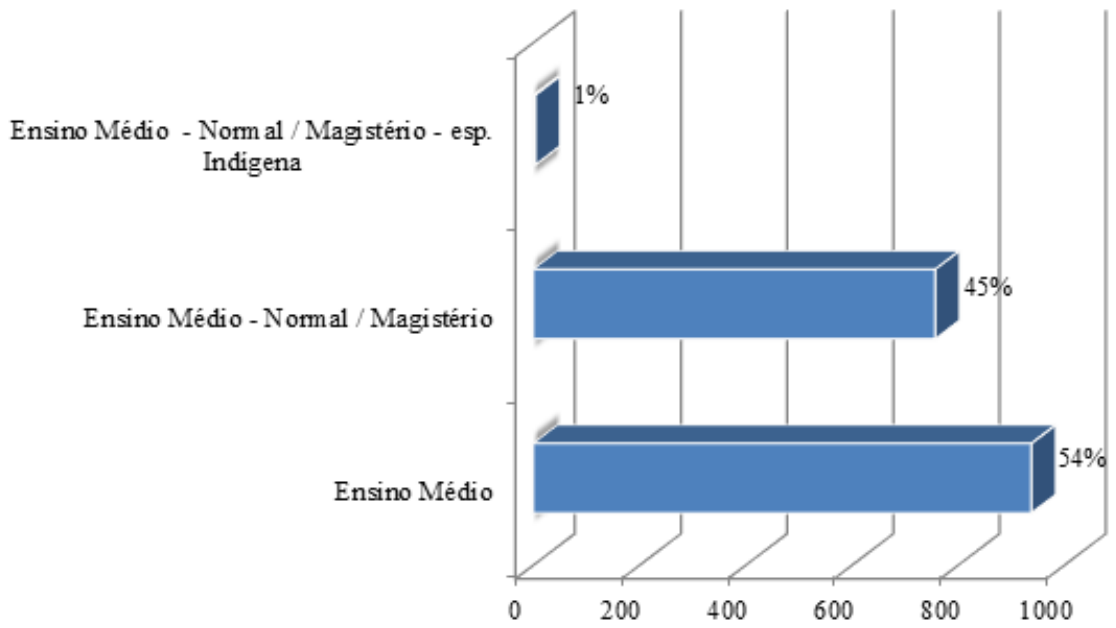

Fonte: adaptado do Instituto Nacional de Estudos e Pesquisas Educacionais Anísio Teixeira (2013).

Evidencia-se, também, no Gráfico 2, outra fragilidade referente à formação inicial desses professores, em que mais da metade (54\%) realizaram o curso de Ensino Médio. Esse percentual, que equivale a 938 professores, preocupa, porque, do ponto de vista legal, o artigo 62 da LDB/96 fixa como formação mínima a obtida em nível superior ou em nível médio modalidade Normal para atuação na Educação Infantil e nos Anos Iniciais do Ensino Fundamental. Por se tratar de Ensino Médio e não de um curso de formação de professores, o currículo não contempla a base teórico-prática para formação docente de forma geral e, tampouco, para uma formação que exige o domínio dos processos de alfabetização.

Além desse percentual de professores formados no Ensino Médio, outros 46\%, que equivalem a 737 professores, são formados no Ensino Médio, em curso Normal. Historicamente, a exigência mínima para a docência nas classes de alfabetização era Ensino Médio em curso Normal. Na concepção de Brzezinsk (2014, p. 1248),

[...] causa estranhamento, todavia, que a legislação brasileira admita, no sistema público, normalistas formados em nível médio, como professores da educação infantil e dos cinco anos do ensino fundamental.

Esse ordenamento legal contrapõe-se à Anfope que, como sujeito social coletivo, desde 1983, reivindica que o ingresso no sistema público seja somente de professores formados em nível 
superior, em cursos oferecidos pela universidade, espaço de produção da ciência, do livre pensamento, da criatividade.

Estudos e pesquisas mostraram, nas últimas décadas, não ser suficiente essa formação, o que definiu a necessidade de uma formação mais consistente, sustentada na indissociabilidade entre ensino, pesquisa e extensão e na articulação entre a Educação Básica e a Superior.

Nesse sentido, importante lembrar as manifestações realizadas por ocasião da tramitação da LDB, em que as entidades integrantes do Fórum Nacional em Defesa da Escola Pública, em especial a Anfope, defendiam a necessidade da formação de professores em nível superior, em cursos de licenciatura plena, na universidade, assim mencionada por Brzezinsk (2008, p. 1147): " [...] a universidade consolida-se como instituição clássica de formação de professores na modalidade inicial compromissada com o desenvolvimento da pesquisa articulada ao ensino e à extensão."

Outro relevante aspecto consiste na formação dos professores alfabetizadores em nível superior. Os 15.235, equivalentes aos 89\% do Gráfico 1, obtiveram formação em diferentes cursos, conforme pode ser observado a seguir:

Gráfico 3 - Formação dos professores alfabetizadores de Santa Catarina

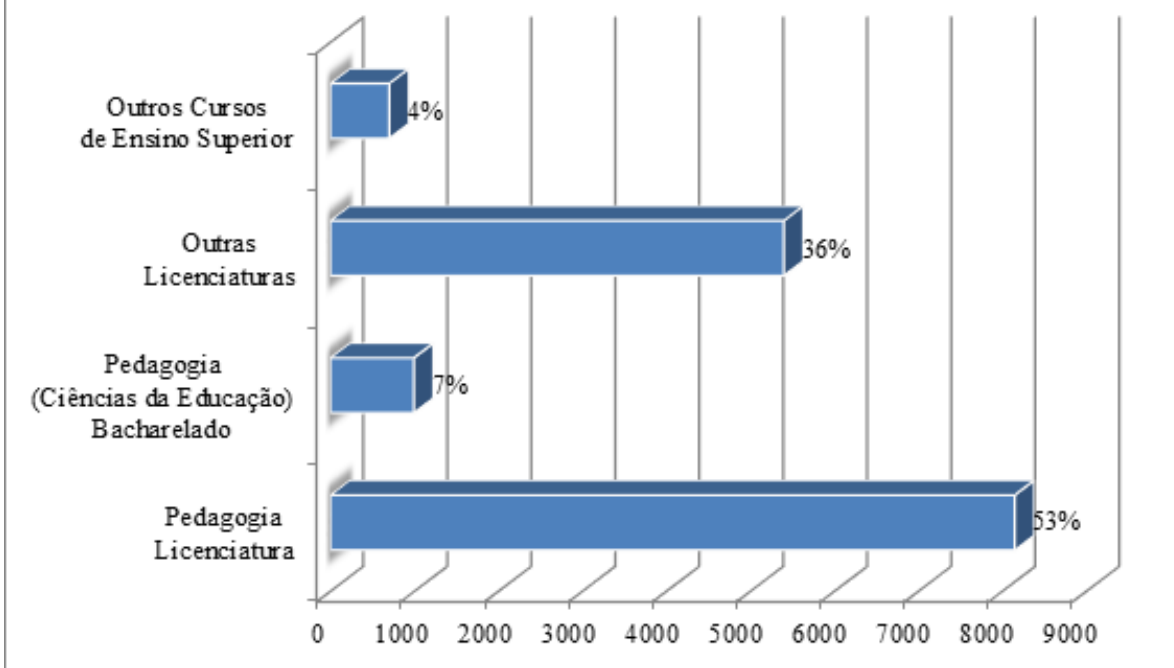

Fonte: adaptado do Instituto Nacional de Estudos e Pesquisas Educacionais Anísio Teixeira (2013).

O Gráfico 3 indica mais uma fragilidade na formação dos professores alfabetizadores, pois apenas pouco mais da metade dos formados em nível superior 
(53\%), equivalente a 8.146 professores, possui formação em Curso de Pedagogia. Os demais 7.089 (47\%) são formados em outros cursos superiores. Ainda que parte desses professores tenha obtido sua formação em diferentes licenciaturas, como mostra o Gráfico 2, destaca-se que o locus, por excelência, de acordo com o requisito legal para a formação do professor para atuar nos anos iniciais, é o Curso de Pedagogia.

Essas fragilidades aqui apontadas - formação no Ensino Fundamental, formação no Ensino Médio e formação em nível superior em diferentes licenciaturas que não a Pedagogia - permitem afirmar que a formação mínima exigida por lei não está sendo cumprida no Estado catarinense na sua totalidade. Além disso, outras consequências decorrem desse quadro, uma delas é a não garantia da aquisição de conhecimentos básicos para o exercício da docência, no caso do professor alfabetizador, a formação específica para a docência em classes de alfabetização. Diante desses dados surgem algumas inquietações, entre elas, como assegurar a alfabetização nos três primeiros anos do Ensino Fundamental? Tendo como base o Parecer n. 4/2008, esses três primeiros anos devem garantir a alfabetização e o letramento das crianças. Assim, há que se considerar que será necessário maior empenho das políticas de formação para que se consiga atender a essa tarefa. Estudos e pesquisas sobre alfabetização desenvolvidos por Magda Soares desde a década de 1980 apontam que é preciso mais que alfabetizar, é necessário alfabetizar de maneira que a criança aproprie-se "[...] da cultura escrita, fazendo um uso real da leitura e da escrita como práticas sociais." (SOARES, 2004, p. 24). Esse entendimento da autora é que se constitui a base da concepção de alfabetização e letramento.

Um professor, para realizar uma prática pedagógica na perspectiva da alfabetização e do letramento, necessitará de conhecimento teórico sobre essa perspectiva, o que, de imediato, remete a uma formação em curso superior na universidade, pois não se trata de uma técnica de alfabetização, mas de uma concepção teórico-metodológica a qual exige a formação que tem na relação teoria-prática a sua base. E esse espaço de formação, conforme já mencionado neste texto, é o Curso de Licenciatura em Pedagogia realizado na universidade. A natureza do curso de Ensino Médio, cujo currículo não contempla a formação de professores, não permite realizar uma formação cuja complexidade exige cursos criados para esse fim.

Outra dimensão analisada referente à formação dos professores alfabetizadores a partir dos dados obtidos no Censo Escolar constitui-se no período em que esses professores realizaram o Curso de Licenciatura em Pedagogia. Isto porque, no contexto das políticas educacionais, como já dito, há vários projetos em disputa, com dimensões político-ideológicas diferenciadas que interferem na elaboração das dire- 
trizes curriculares nacionais para os Cursos de Pedagogia, evidenciando alternância dessas posições em cada momento histórico. Mesmo as diretrizes sendo a expressão teórica de um desses projetos, não necessariamente se materializa na prática porque a realidade é dinâmica e essas posições em disputa fazem-se presentes em todos os setores da sociedade, donde não se excluem os cursos de formação de professores e as escolas.

Gráfico 4 - Ano de conclusão do Curso de Pedagogia dos professores alfabetizadores de Santa Catarina em exercício no ano 2013

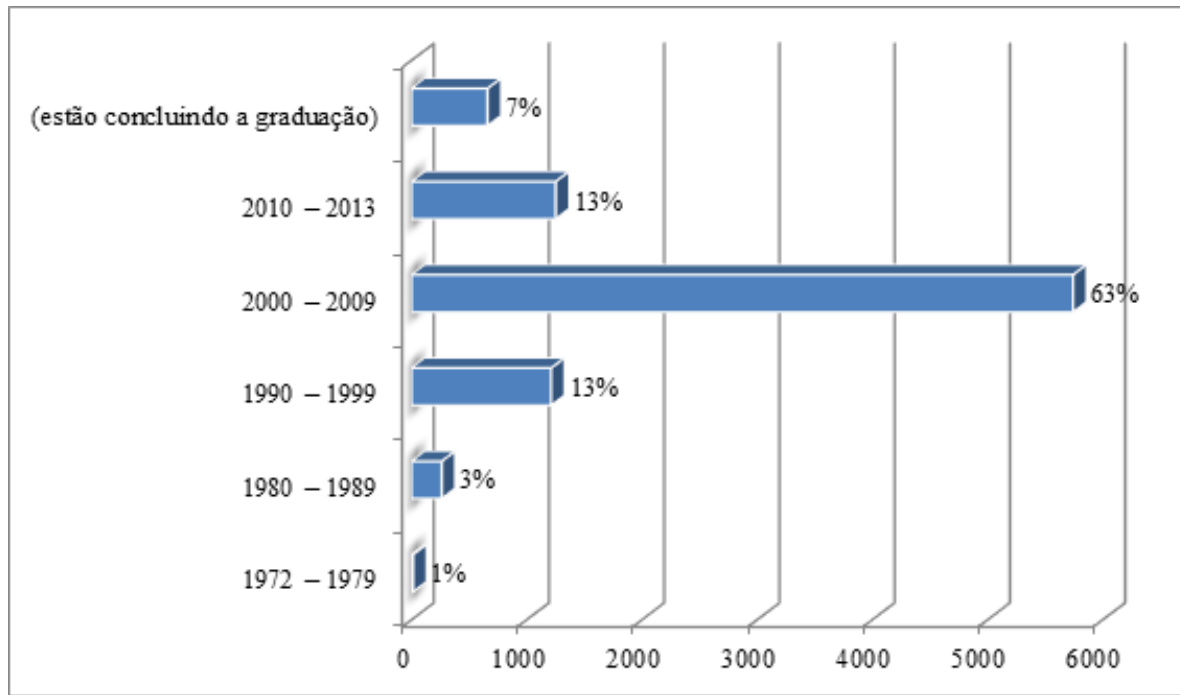

Fonte: adaptado do Instituto Nacional de Estudos e Pesquisas Educacionais Anísio Teixeira (2013).

Percebe-se que do total dos professores com Ensino Superior em Pedagogia, $0,15 \%$ concluiu sua formação inicial na década de $1970 ; 2,87 \%$, na década de $1980 ; 13,25 \%$, na década de 1990; 62,83\%, na primeira década do século XXI e $13,69 \%$, entre 2011 e 2013 . O restante, correspondente a 7,21\%, não informou o ano de conclusão de sua formação. Constata-se, também, que o período em que ocorreu a formação dos professores foi entre 1972 e 2013, visto que a maioria obteve o diploma de 1990 em diante.

O maior número de egressos a partir de 1990 deve ser expressão das exigências do parágrafo $4^{\circ}$, do artigo 87, da LDB - Lei n. 9.394/96 (vetado pela Lei n. 12.796, de 04 de abril de 2013), que determinava que “[...] até o fim da Década da 
Educação somente serão admitidos professores habilitados em nível superior ou formados por treinamento em serviço." (BRASIL, 1996).

A exigência prevista no artigo 87 demandou a necessidade de aumento considerável de criação de cursos superiores de formação de professores, definindo o imediato aumento de matrículas e egressos, e pode ter contribuído para o "aligeiramento" da formação inicial dos professores alfabetizadores, como destacado nos estudos de Saviani, já mencionado neste texto. Nesse contexto é que ocorreu também a abertura de cursos de finais de semana e férias dos professores. Exemplo disso foi o Programa Magister, cujo funcionamento foi aprovado pelo Parecer n. 141, de 23 de abril de 1996, do Conselho Estadual de Educação de Santa Catarina. Esse Programa realizou-se por meio de parceria entre o Estado de Santa Catarina e Instituições de Ensino Superior (IESs) desse Estado com o objetivo de promover uma formação docente em serviço. As Instituições são: Universidade Federal de Santa Catarina (UFSC), Universidade do Estado de Santa Catarina (Udesc) e Universidades comunitárias distribuídas nas diferentes regiões do Estado.

Além dessa expansão, criou-se, no Brasil, o curso de licenciatura na modalidade de Educação a Distância (EaD), que também vem contrariar as diretrizes das entidades anteriormente citadas as quais propõem a formação inicial de professores na modalidade presencial. Assim, a necessidade de formação inicial de um grande contingente de docentes abriu a possibilidade de criação de cursos pela iniciativa privada, contribuindo para a expansão inédita do "mercado" do ensino superior, o que reflete o contexto político e econômico mais amplo da globalização e suas consequências no mundo do trabalho.

Nesse período de aumento considerável de cursos e matrículas para a formação de professores, diretrizes, resoluções e programas de formação oficiais foram formulados a partir das determinações dos organismos internacionais que buscavam interferir para materializar nas políticas educacionais as exigências do mundo do trabalho e as estratégias do capital. Esses documentos oficiais deslocam a discussão dos conteúdos de formação sustentados na relação teoria-prática para uma formação com base no desenvolvimento de competências para lidar com as técnicas e os instrumentais do ensino (tecnologia) e da ciência aplicada no campo do ensino e da aprendizagem, incluindo a visão instrumental da investigação e da pesquisa (SCHMIDT; AGUIAR, 2014).

Diferentemente, cumpre valorizar a formação dos professores à luz do papel que joga a universidade à produção do conhecimento, em geral, e, em particular, ao que se refere a uma formação docente consistente e teórica que possa contribuir 
para uma educação de qualidade para crianças, jovens e adultos, como direito inalienável da pessoa humana.

Acompanhando a tendência nacional, também em Santa Catarina a privatização dos cursos de formação de professores amplia-se consideravelmente, como mostra a Tabela 1:

Tabela 1 - Dependência administrativa das IESs da formação dos professores alfabetizadores de Santa Catarina - 2013

\begin{tabular}{lll}
\hline Dependência administrativa & N. de professores & $\%$ \\
\hline Pública & 1.611 & 10 \\
Privada & 13.624 & 90 \\
Total & 15.235 & 100 \\
\hline
\end{tabular}

Fonte: Silveira (2015, p. 67).

De acordo com os dados da Tabela 1, 10\% dos professores obtiveram sua formação em instituições públicas. Destas, 34 são federais; 21, estaduais e 3, municipais, em um total de 58 IESs. Já a maioria dos professores alfabetizadores, o equivalente a 90\%, realizou sua formação em 319 instituições privadas diferentes, indicando um número elevado de locais diferentes em que ocorreu a formação desses professores alfabetizadores, além de evidenciar a diferença entre o número de instituições públicas e privadas no Estado.

Se o número de instituições do local da formação desses professores é elevado, também a definição quanto ao tipo é significativa. Dos 9.138 professores alfabetizadores formados em Pedagogia, 4.492 formaram-se em universidades; 1.323, em centros universitários; 928, em faculdades; 65, em institutos superiores de educação; 10, em centros de ensino superior; 4, em escolas superiores; 1 , em centro de pós-graduação e os demais 2.315 professores não indicaram o tipo de instituição em que estudaram.

Essa diversificação das instituições atende ao artigo 62 da LDB, que define que a formação do pedagogo deve ser realizada em "[...] nível superior, em curso de licenciatura, de graduação plena, em universidades e institutos superiores de educação.” (BRASIL, 1996, grifo nosso).

Segundo o Decreto n. 5.773/06, que dispõe sobre o exercício das funções de regulação, supervisão e avaliação de instituições de Educação Superior e cursos superiores de graduação e sequenciais no sistema federal de ensino, há significativa diferença entre os tipos de instituições. 
[...] as instituições de ensino superior, de acordo com sua organização e respectivas prerrogativas acadêmicas, são credenciadas como:

I - faculdades;

II - centros universitários; e

III - universidades.

[...] As universidades se caracterizam pela indissociabilidade das atividades de ensino, pesquisa e extensão. São instituições pluridisciplinares de formação dos quadros profissionais de nível superior, de pesquisa, de extensão e de domínio e cultivo do saber humano, que se caracterizam por:

I - produção intelectual institucionalizada mediante o estudo sistemático dos temas e problemas mais relevantes, tanto do ponto de vista científico e cultural quanto regional e nacional;

II - um terço do corpo docente, pelo menos, com titulação acadêmica de mestrado ou doutorado; e

III - um terço do corpo docente em regime de tempo integral. (BRASIL, 2006).

Considerando o Decreto, verifica-se que a formação a se realizar em universidades deve ocorrer cumprindo a indissociabilidade entre ensino, pesquisa e extensão, bem como o estudo da realidade regional. Outro diferencial que caracteriza as instituições credenciadas como universidades é o da titulação do corpo docente, em que um terço deve ser formado por mestres ou doutores com regime contratual em tempo integral.

Já os centros universitários são caracterizados como:

[...] instituições de ensino superior pluricurriculares, abrangendo uma ou mais áreas do conhecimento, que se caracterizam pela excelência do ensino oferecido, comprovada pela qualificação do seu corpo docente e pelas condições de trabalho acadêmico oferecidas à comunidade escolar. Os centros universitários credenciados têm autonomia para criar, organizar e extinguir, em sua sede, cursos e programas de educação superior. (BRASIL, 2006).

A formação realizada em centros universitários, institutos, faculdades e escolas de Ensino Superior não seguem a lógica da indissociabilidade entre ensino, pesquisa e extensão, nem contam com quadro de professores com formação mínima em mestrado e doutorado, o que pode possibilitar uma formação "aligeirada e inconsistente", sem base na pesquisa, portanto, questionada na qualidade.

De acordo com Aguiar e Scheibe (2010, p. 80), os documentos da Anfope têm apontado exaustivamente que

[...] a concepção de formação para os profissionais da educação envolve o desenvolvimento de sólida formação teórica e interdisciplinar em educação [...]; unidade entre teoria e prática 
na formação, pela centralidade do trabalho como princípio educativo; pesquisa como princípio cognitivo e eixo nucleador da formação.

Conforme dados apresentados anteriormente, praticamente metade dos professores alfabetizadores de Santa Catarina teve sua formação em Pedagogia na universidade (4.492 do total de 9.138). Ainda que em torno de 50\% desses professores tenham obtido sua formação em universidade, o que se compreende como fundamental, e ainda que a lei permita a formação em outros tipos de instituição não universitária, os estudos sobre os quais se referenciou apontam para uma formação inconsistente do ponto de vista teórico.

Nessa perspectiva, no cotidiano das escolas públicas o conhecimento historicamente produzido vai sendo trabalhado de forma fragmentada, perdendo sua dinamicidade e importância como suporte para a análise e a compreensão da realidade.

\section{CONSIDERAÇÕES FINAIS}

Após a análise da formação inicial dos professores alfabetizadores de Santa Catarina em exercício no ano 2013, a partir dos dados obtidos no Censo Escolar, evidencia-se que a formação exigida para o exercício da docência nas classes de alfabetização não é atendida nem mesmo no que se refere à titulação mínima. Há, ainda, um contingente significativo de professores leigos no Estado, ou seja, não têm formação em Cursos de Pedagogia ou curso de nível médio modalidade Normal conforme preconiza o artigo 62 da LDB/96.

Em especial, para o exercício da docência nas classes de alfabetização de modo que seja assegurada às crianças a apropriação da leitura e da escrita com condições de fazer uso em diferentes situações e contextos, fazem-se necessárias, ainda, políticas para a implementação de medidas que garantam a formação consistente para todos os professores.

A busca por uma escola pública de qualidade social para todos, reivindicada pelas entidades da educação, evidencia a necessidade de continuidade de enfrentamentos dos desafios por uma sólida e consistente formação dos professores, nesse caso, de professores alfabetizadores que atuam nos Anos Iniciais do Ensino Fundamental. Neste artigo, procurou-se apontar e refletir sobre alguns desses desafios em relação à formação do professor alfabetizador, dentro dos limites que o espaço de um artigo permite. 
Notas explicativas:

${ }^{1}$ O Parecer CNE/CEB n. 4/2008, de 20 de fevereiro de 2008, estabelece o $1^{\circ}$ ano do Ensino Fundamental como parte integrante de um ciclo de três anos de duração denominado "ciclo da infância" e ressalta os três anos iniciais como um período voltado à alfabetização e ao letramento (BRASIL, 2009).

${ }^{2}$ Theodoro W. Schultz (1902-1998) foi o principal expoente da Teoria do Capital Humano (TCH), nos anos 1950, nos Estados Unidos. Para este, a produção e, consequentemente, os lucros poderiam ser aumentados mediante o trabalho humano qualificado pela educação, pois compreende que o Capital Humano é " [...] a soma dos investimentos do indivíduo em aquisição de conhecimentos e que a qualquer momento reverte em benefícios econômicos para o próprio indivíduo.” (AGUIAR, 2012, p. 12).

${ }^{3}$ Conselho Nacional de Educação.

${ }^{4}$ Conselho Pleno.

\section{REFERÊNCIAS}

AGUIAR, L. C. Formação docente, política curricular e a reedição da teoria do capital humano no Brasil. Cadernos de Pesquisa em Educação - PPGE/UFES, Vitória, ano 9, v. 18, n. 36, p. 11-32, jul./dez. 2012. Disponível em: <http://periodicos.ufes.br/educacao/article/view/5372/3972>. Acesso em: 15 ago. 2016.

AGUIAR, L. C. Um legado do século XX para a política educacional do século XXI: a teoria do Capital Humano. Revista HISTEDBR On-line, Campinas, n. 40, p. 126-144, dez. 2010. Disponível em: <http://www.histedbr.fe.unicamp.br/revista/ edicoes/40/art08_40.pdf>. Acesso em: 09 fev. 2015.

AGUIAR, M. A. de S.; SCHEIBE, L. Formação e valorização: desafios para o PNE 2011/2020. Revista Retratos da Escola, Brasília, DF, v. 4, n. 6, jan./jun. 2010.

ASSOCIAÇÃO NACIONAL PELA FORMAÇÃO DOS PROFISSIONAIS DA EDUCAÇÃO. Formação dos profissionais da educação e base comum nacional: construindo um projeto coletivo. In: ENCONTRO NACIONAL DA ANFOPE DOCUMENTO FINAL, 11., 2002, Florianópolis. Anais... Florianópolis, 2002. Disponível em: <anfope.com.br/wpcontent/uploads/2014/08/doc_final_xi.doc $>$. Acesso em: 09 fev. 2015.

ASSOCIAÇÃO NACIONAL PELA FORMAÇÃO DOS PROFISSIONAIS DA EDUCAÇÃO. Política Nacional de Formação e Valorização. Documento da Anfope ao CNE. Campinas, 2014. Disponível em: <http://anfope.com.br/documentos/documentos-oficiais/documentos-de-politicas-de-formacaopara-professores/documento-da-anfope-ao-cne-politica-nacional-de-formacao-e-valorizacaoem-marco-2014/>. Acesso em: 25 abr. 2016.

BRASIL. Decreto n. 5.773, de 09 de maio de 2006. Dispõe sobre o exercício das funções de regulação, supervisão e avaliação de instituições de educação superior e cursos superiores de graduação e sequenciais no sistema federal de ensino. Diário Oficial da União, Brasília, DF, 10 maio 2006. Disponível em: <http://www.planalto.gov.br/ ccivil_03/_ato2004-2006/2006/decreto/d5773.htm>. Acesso em: 15 dez. 2014. 
BRASIL. Lei n. 9.394, de 20 de dezembro de 1996. Estabelece as diretrizes e bases da educação nacional. Diário Oficial da União, Brasília, DF, 23 dez. 1996. Disponível em: <http://portal.mec.gov.br/arquivos/pdf/ldb.pdf>. Acesso em: 09 jun. 2014.

\section{BRASIL. Secretaria de Educação Básica. Ensino Fundamental de Nove}

Anos: Passo a Passo do Processo de Implantação. Diretoria de Concepções e Orientações Curriculares para Educação Básica. Coordenação-Geral do Ensino Fundamental. Brasília, DF: Ministério da Educação, 2009. Disponível em: < http:// portal.mec.gov.br/index.php?option $=$ com_docman\&view $=$ download\&alias $=700$ -

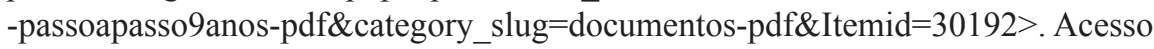
em: 03 mar. 2016.

BRZEZINSK, I. Políticas contemporâneas de formação de professores para os anos iniciais do ensino fundamental. Educ. Soc., Campinas, v. 29, n. 105, p. 1139-1166, set./dez. 2008. Disponível em: <http://www.scielo.br/pdf/es/v29n105/v29n105a10. pdf>. Acesso em: 03 mar. 2016.

BRZEZINSK, I. Sujeitos sociais coletivos e a política de formação inicial e continuada emergencial de professores: contradições vs conciliações. Educação e Sociedade, Campinas, v. 35, n. 129, p. 1241-1259, out./dez. 2014. Disponível em: <http:// www.scielo.br/pdf/es/v35n129/0101-7330-es-35-129-01241.pdf>. Acesso em: 09 ago. 2016.

BRZEZINSK, I. Tramitação de desdobramentos da LDB/1996: embates entre projetos antagônicos de sociedade e de educação. Trab. Educ. Saúde, Rio de Janeiro, v. 8, n. 2, p. 185-206, jul./out. 2010. Disponível em: <http://www.scielo.br/pdf/tes/ v8n2/a02v8n2.pdf>. Acesso em: 03 mar. 2016.

CÂMARA DOS DEPUTADOS. Lei n. 13.005, de 25 de junho de 2014. Aprova o Plano Nacional de Educação - PNE e dá outras providências. Diário Oficial da União, Brasília, DF, 26 jun. 2014. Disponível em: <http://www.planalto.gov.br/CCIVIL_03/_Ato2011-2014/2014/Lei/L13005.htm>. Acesso em: 07 maio 2016.

FREITAS, H. C. L. Formação de Professores no Brasil: 10 anos de embate entre projetos de formação. Educação e Sociedade, Campinas, v. 23, n. 80, p. 136-167, set. 2002. Disponível em: <http://www.scielo.br/pdf/es/v23n80/12928.pdf > . Acesso em: 23 out. 2014 .

INSTITUTO NACIONAL DE ESTUDOS E PESQUISAS EDUCACIONAIS ANÍSIO TEIXEIRA. Microdados do Censo Escolar 2013. Disponível em: $<$ http:// portal.inep.gov.br/basica-levantamentosacessar>. Acesso em: 02 abr. 2014.

OLIVEIRA, D. A. (Org.). Gestão democrática da educação. 8. ed. Petrópolis: Vozes, 2008. 
PLANO DECENAL DE EDUCAÇÃO PARA TODOS. Brasília, DF: MEC, Unesco, 1993. Disponível em: <http://www.dominiopublico.gov.br/download/texto/ me001523.pdf>. Acesso em: 06 mar. 2016.

SAVIANI, D. Formação de professores: aspectos históricos e teóricos do problema no contexto brasileiro. Revista Brasileira de Educação, v. 14, n. 40, jan./abr. 2009. Disponível em: <http://www.scielo.br/pdf/rbedu/v14n40/v14n40a12.pdf > . Acesso em: 03 mar. 2016.

SCHMIDT, L. L; AGUIAR, L. C. A formação continuada de professores dos anos iniciais da educação fundamental no Brasil. Tabanque Revista Pedagógica, n. 27, 2014. Disponível em: $<$ https://dialnet.unirioja.es/servlet/articulo? codigo $=5084325>$. Acesso em: 03 mar. 2016.

SHIROMA, E. O. Educação profissional e profissionalização de educadores. Revista Perspectiva, v. 18, n. 33, 2000. Disponível em: <http://www.periodicos.ufsc.br/ index.php/perspectiva/article/view/9386/8638>. Acesso em: 18 mar. 2013.

SHIROMA, E. O.; MORAES, M. C. M. de; EVANGELISTA, O. Política Educacional. 2. ed. Rio de Janeiro: DP\&A, 2002.

SILVEIRA, C. M. O perfil dos professores alfabetizadores das escolas públicas de Santa Catarina. 2015. 112 p. Dissertação (Mestrado em Educação)-Universidade do Sul de Santa Catarina, Tubarão, 2015.

SOARES, M. Letramento e alfabetização: as muitas facetas. Revista Brasileira de Educação, 2004. Disponível em: <http://www.scielo.br/pdf/rbedu/n25/n25a01. pdf/>. Acesso em: 04 maio 2015.

Recebido em: 20 de maio de 2016 Aceito em: 02 de setembro de 2016

Endereço para correspondência: Avenida José Acácio Moreira, 787, Dehon, 88704900, Tubarão, Santa Catarina, Brasil; leonetes@gmail.com 
